\title{
Percepción de los estudiantes de Maestro de Educación Primaria sobre su competencia digital: urgencias formativas detectadas
}

\section{The perceptions of Primary School Degree students about their digital competence: detection of training necessities}

\author{
JaVier Fombona ${ }^{1}$ \\ fombona@uniovi.es \\ Maria Angeles Pascual \\ apascual@uniovi.es \\ Universidad de Oviedo, España
}

\section{Resumen:}

INTRODUCCIÓN. El dinamismo del fenómeno de las nuevas tecnologías aplicadas a la educación obliga a la comunidad académica a revisar de forma sistemática el nivel de dominio de los estudiantes sobre las competencias relacionadas. Este trabajo forma parte de una amplia investigación que analiza la formación sobre nuevas tecnologías que posee el alumnado del Grado de Maestro de Educación Primaria en tres universidades españolas (Granada, Jaén y Oviedo). METODO. El estudio se centra en una muestra de 559 estudiantes y pone en relieve las fortalezas y debilidades que tienen actualmente en materia TIC, haciendo énfasis en aquellos aspectos que deben ser objeto de especial atención didáctica. RESULTADOS. Los resultados muestran nuevos retos para el docente, ya sean aspectos técnicos, legislativos, o cuestiones relacionadas con la

\begin{abstract}
:
INTRODUCTION. The application of new technologies to education is a dynamic phenomenon and this forces the academic community to constantly review students real knowledge of their competences. This article is part of an extensive research project that analyzes the ICT training received by Primary Education Degree Students at three Spanish universities (Granada, Jaén and Oviedo). METHOD. The study included a sample of 559 students and highlighted the strengths and weaknesses regarding their ICT skills, emphasizing those aspects that have a bigger impact on these students' pedagogical performance. RESULTS. The results show new challenges for teachers, whether technical, legislative, or about security-related issues, such as cyberbullying or anxiety. DISCUSSION. The increase in contents should not be an obstacle to continue addressing tra-
\end{abstract}

1 Dirección para correspondencia (correspondence address):

Javier Fombona. Universidad de Oviedo. Departamento de Ciencias de la Educación. Facultad de Formación del Profesorado y Educación. Campus de de Llamaquique. C/ Aniceto Sela, s/n. 33005 Oviedo (España). 
Percepción de los estudiantes de Maestro de Educación Primaria sobre su competencia digital: urgencias formativas detectadas

Javier Fombona y Maria Angeles Pascual

seguridad, tales como el acoso o la ansiedad derivada. DISCUSIÓN. Este incremento de contenidos no debe ser óbice para continuar abordando temas TIC tradicionales y de elevado impacto, dado que los datos indican que esos aspectos se vuelven nuevamente lagunas del conocimiento.

\section{Palabras clave:}

Competencia Digital; Educación Primaria; Formación del Profesorado; TIC; Nuevas Tecnologías Aplicadas a la Educación. ditional ICT issues, since our results show these issues become gaps in students' knowledge recurringly.

\section{Keywords:}

Digital Competence; Primary School; Teacher training; ICT; New technologies applied to education.

\section{Résumé:}

INTRODUCTION. Les nouvelles technologies appliquées à l'éducation sont un phénomène dynamique, ce qui oblige la communauté académique à revoir le niveau de connaissances des élèves par rapport à leurs compétences réelles. Ce travail fait partie $d^{\prime}$ 'une recherche approfondie qui analyse la formation aux TIC des élèves de la formation des enseignants du primaire, dans trois universités espagnoles (Grenade, Jaén et Oviedo). MÉTHODE. L'étude se concentre sur un échantillon de 559 étudiants et met en évidence les forces et les faiblesses de leurs compétences en TIC, en insistant sur les aspects qui devraient être spécialement étudiés. RÉSULTATS. Les résultats montrent de nouveaux défis pour l'enseignant, sur les plans technique, législatif ou lié à la sécurité, tels que le cyberharcèlement ou l'anxiété. DISCUSSION. Cette augmentation du nombre de matières ne doit pas empêcher de continuer à aborder les questions traditionnelles des TIC, car nos résultats montrent que ces aspects redeviennent des lacunes dans les connaissances des étudiants.

\section{Mots clés:}

Compétence numérique; École primaire; Formation des enseignants; TIC; Nouvelles technologies appliquées à l'éducation.

Fecha de recepción: 30-04-2020

Fecha de aceptación: 03-06-2020

\section{Introducción}

Las competencias aparecen en las programaciones didácticas como relevo a los tradicionales planteamientos docentes por objetivos (Sierra, Méndez-Giménez y Mañana-Rodríguez, 2012). Son concreciones de realidades complejas. Así, la competencia digital es una capacidad multidimensional de las personas que engloba un conjunto de acciones muy variadas, afecta a todos los niveles educativos, y reúne múltiples tendencias relacionadas con las metodologías, los recursos, instrumentos y contenidos docentes. El término competencia hace referencia al 
dominio en la realización de determinada manera de una actividad. Esta capacidad no implica necesariamente un ejercicio correcto de esa tarea, por ello es preciso matizar que somos capaces de realizarla forma adecuada, ya que en caso contrario seríamos escasamente competentes en su desempeño. Por tanto, la actual tendencia a la formación en competencias encierra una ambigüedad, y debe complementarse con el matiz de la competencia adecuada o eficaz. En caso contrario la competencia puede tener un componente negativo, y ser limitada, incorrecta o imperfecta. Esa ambigüedad del término debe concretarse con unas características de desempeño y unos valores de la propia competencia. No debemos olvidar que la unidad de competencia tiene especial relación con la formación profesional donde este término delimita un grupo de tareas susceptibles de reconocimiento, y agrupadas que configuran un determinado Certificado de Profesionalidad dentro del Catálogo Nacional de Cualificaciones Profesionales elaborado por el INCUAL español. En el ámbito universitario se utiliza el término competencia desde un planteamiento investigador (Pérez Ferra, 2013), como un ejercicio adecuado de una actividad, sin encajarse en ningún catálogo elaborado por una institución única. La competencia digital vinculada a los niveles educativos medios se ha descrito un Marco Común de Competencia Digital Docente (INTEF, 2015) que ha sido y es objeto de debate sobre sus dimensiones.

Por otro lado, el término digital contiene también una elevada ambigüedad, y desde hace años engloba todo un conjunto de procedimientos, máquinas, aplicaciones, actitudes e ideas que en ocasiones son de difícil compaginación, y que pudieran no estar diseñadas para el ámbito educativo (Fombona, 2003). Así, las tecnologías tienen una naturaleza y forma de presentación múltiple, inicialmente orientada al ocio, al trabajo o a la comunicación. El Consejo de la Unión Europea orienta la competencia digital al uso "seguro de las Tecnologías de la Sociedad de la Información en el trabajo, ocio y la comunicación, y más concretamente al uso de ordenadores para recuperar, evaluar, almacenar, producir, presentar e intercambiar información, y para comunicar y participar en redes de colaboración en Internet" (Consejo de la Unión Europea, 2006).

En el ámbito educativo nos encontrarnos y asumimos varias formas de estos recursos, ya sean audiovisuales, herramientas telemáticas, equipos informáticos de cómputo, materiales periféricos tales como instrumentos de visualización, de impresión, etc. Toda esta complejidad se hace 
Percepción de los estudiantes de Maestro de Educación Primaria sobre su competencia digital: urgencias formativas detectadas

Javier Fombona y Maria Angeles Pascual

más laberíntica al ser objeto de una evolución rápida que nos somete a renovaciones constantes de ese instrumental, a cambios en su funcionamiento, su filosofía y a nuevos impactos sociales variados en cantidad y tipología. Todo ello nos lleva a un constante proceso de investigación y exploración de sus posibilidades reales, fenómeno denominado alfabetización digital (Cuartero, Gutiérrez y Prendes, 2016), que nos sugiere un planteamiento de codificación y decodificación, de lectura y escritura (Ferrari, 2012).

La competencia digital recibe diversas denominaciones, como competencia TIC, tecnológica, informática, informacional, etc. Parece ser una competencia transversal necesaria en otros ámbitos, tales como la investigación, la comunicación, o la gestión, y precisamente por ello, necesita de una capacitación especialmente rigurosa y eficaz. En los distintos niveles y áreas educativas, las competencias relacionadas con el uso de las TIC se han vuelto en un tema recurrente transversal y se han convertido en componente fundamental, y esto implica el hecho de abordarlas en las programaciones con planteamientos reduccionistas e importantes limitaciones. Así, han surgido múltiples análisis sobre las competencias de los futuros maestros (Prendes, Castañeda y Gutiérrez, 2010) que se circunscriben a determinados conocimientos de algún aspecto de las TIC. Por ello la competencia digital al englobar aspectos diversos, impulsó a múltiples autores a intentar sus posibilidades educativas en una taxonomía válida que agrupe los conceptos y que fuera asumida por los sistemas educativos (UNESCO, 1984; Gallego-Arrufat, 1995; Legorreta y López, 2005; Comisión Europea, 2006; Vivancos, 2008; Krumsvik, 2011; Gisbert y Esteve, 2011; Gallardo, et al, 2015; Muñoz et al., 2016). Así, suelen abordarse una selección de temas relacionados con la competencia digital que responde a varios criterios pero que no ha logrado el consenso entre los diversos escenarios educativos de implementación. Y se abordan, con distinta profundidad según el nivel educativo, sólo determinados temas, como los usos básicos informáticos, los tratamientos de textos, las hojas de cálculo, las bases de datos, las presentaciones, etc. Actualmente se han incorporado otras materias de actualidad, tales como los dispositivos móviles, nuevas aplicaciones como la realidad aumentada, los equipos específicos sean para la impresión o la virtualización, etc. En pocos casos se abordan cuestiones técnicas y el docente sigue enfrentándose a las máquinas como las grandes barreras de la docencia cotidiana (Fombona, Rodríguez y Barriada, 2012). Por otro 
el impacto social del fenómeno tecnológico lleva en muchos casos a convertir la competencia digital en estudios crítico cargado de planteamientos ideológicos, que se separa de los análisis rigurosos sobre casos específicos.

Actualmente, todo este mosaico tecnológico se integra en el multimedia, donde es difícil desligar la variable información de la comunicación, o de la creación de contenidos. También quedan desdibujadas las fronteras entre variables tales como la resolución de problemas digitales, la seguridad, la autoría, etc. Es en este escenario donde el docente debe hacer su desempeño profesional, bien sea para formar estudiantes en los diversos niveles educativos, futuros ciudadanos, o para formar a los futuros maestros y maestras. Aquí la competencia digital se debe compaginar con competencias tradicionales de trabajo en el aula, tales como el trabajo autónomo, el trabajo colaborativo, la capacidad comunicativa, y otras más específicas, como el dominio del idioma inglés, por poner un ejemplo. Por último, si hacemos referencia al nivel educativo superior, las competencias en el ámbito universitario deben abordar dominios más complejos, relacionados con el diseño, la gestión, la investigación, la evaluación y la innovación (Pozos, 2009). Aquí se deben conjugar nuevas dimensiones interrelacionadas, tales como la internacionalización, la competitividad, o la denominada bibliotecnología (Gisbert, Espuny y González, 2011).

\section{Justificación}

Las investigaciones de hace una década, que en otras áreas pudieran tener vigencia, se vuelven caducas ante las TIC. Ante un panorama tan complejo y dinámico como el descrito, se hace obligatorio que la comunidad académica de respuestas concretas a la sociedad ante los efectos de las tecnologías, y de respuesta a las instituciones que demandan formación en cualificaciones precisas (Pérez Ferra y Pantoja, 2006; García, Pascual y Fombona, 2011). Por otro lado, no sólo en las universidades de referencia, se han detectado carencias epistémico-ontológicas en el profesorado. Son necesidades en el saber sobre cómo plantear la adquisición de conocimientos con relación a las TIC, y sobre todo, en conocer cuáles son las carencias reales de su alumnado. Por ello, se precisa una investigación actualizada que despeje estas incertidumbres (Pozue- 
Percepción de los estudiantes de Maestro de Educación Primaria sobre su competencia digital: urgencias formativas detectadas

Javier Fombona y Maria Angeles Pascual

los, Través y Cañal, 2010; Dolana, 2012; Kim et al. 2013). Estas lagunas en el conocimiento han sido descritas en los trabajos previos e indican que el profesorado se reconoce no experimentado para ir integrando interdisciplinarmente en el curriculum contenidos y acciones formativas, considerando la especial velocidad en la renovación e innovación del fenómeno tecnológico.

\section{Objetivos}

A nivel general se intenta que el alumnado, futuros docentes de Educación Primaria, tengan una mejor cualificación y produzcan un impacto en su alumnado, y por ende en la sociedad, de forma más eficaz. Por ello se pretende aportar pautas para la mejora de las acciones formativas relacionadas con las TIC, y mejora de sus planes de estudio. Los resultados de esta investigación se convierten en un programa formativo en red integrado en el currículum de las universidades participantes. Por otro lado, las aportaciones contribuyen al desarrollo y consolidación del conocimiento epistémico general de estas competencias en los grados de Maestro, en este caso la Competencia para gestionar enseñanza y aprendizaje a través de las TIC.

\section{Método}

La investigación parte de una detección de carencias en materia tecnológica del alumnado, para crear un programa formativo al efecto, su implementación y validación. Con ello se determinan las unidades de competencia relacionadas que realmente son susceptibles de mejora, para lo cual se verifican los resultados finales en grupos experimentales y otros de control, con pretest y post-test. Es una investigación con intervención formativa que extrae diferencias significativas en el desarrollo de competencias consideradas, entre los grupos experimentales usuarios de una formación específica, esto es, estudiantes del grado de Maestro de Educación Primaria y sus correspondientes grupos control, que reciben la formación diseñada en sus currículos ordinarios. Durante el curso, los estudiantes de los grupos experimentales reciben una formación complementaria a través de entornos virtuales para reforzar el desarrollo de 
las competencias propuestas, a partir del nivel manifestado en situación inicial.

Para lograr el objetivo de mejorar la capacitación del alumando es preciso determinar con precisión sus lagunas y realizar un diagnóstico de las necesidades formativas. El estudio se encuadra dentro de las investigaciones con planteamientos mixtos-complementarios, tanto paradigmáticos como metodológicos longitudinales. La detección de carencias en materia TIC es el primer paso para el diseño e implementado acciones educativas al efecto, que aquí no se describen, pero que sirven para verificar que es alcanzable el nivel de competencias sobre las que se han observado carencias.

\section{Muestra y procedimiento}

La investigación se centra en tres escenarios universitarios españoles correspondientes a las Facultades de Educación de Granada, Jaén y Oviedo, y se ha trabajado con 559 estudiantes en el año 2017 dentro del título de Grado de Maestro en Educación Primaria en tales instituciones. Su perfil de corresponde con personas de 18-21 años con un predominio del género femenino. La muestra se ha homogeneizado respondiendo a dos criterios:

1. Estudiantes con una orientación profesional clara para lo cual se priorizan aquellos que eligen ser maestros/as en primera y segunda opción.

2. Estudiantes que manifiesten interés por el proyecto y se comprometan a permanecer y trabajar en las tareas de evaluación y formación posterior.

Inicialmente se realiza un ensayo piloto de validación experimental, que será utilizada en primer lugar para redefinir las realidades epistémicas para concretar cada competencia implicada y determinar las pruebas definitivas. Con la aplicación del instrumento se identifica el nivel de dominio en el alumnado de las habilidades de competencia correspondientes y se priorizan sus necesidades formativas en el desarrollo de las competencias clave en experimentación. 
Percepción de los estudiantes de Maestro de Educación Primaria sobre su competencia digital: urgencias formativas detectadas Javier Fombona y Maria Angeles Pascual

\section{Construcción del instrumento}

El diagnóstico de necesidades formativas comprende el diseño, implementación y validación de pruebas de evaluación inicial, con la selección de indicadores potenciales de la competencia digital. Se usan técnicas de encuesta, análisis de tareas, estudios de caso prototípicos y grupos de discusión. La validez se evidencia mediante estrategias lógicas para obtener el grado de congruencia entre expertos en contenido y medida, seleccionados por su capacidad entre el profesorado de las facultades implicadas. Más específicamente, la recogida de información se lleva a cabo mediante el diseño y aplicación de los siguientes instrumentos y técnicas:

a) Grupos de discusión y análisis por jueces expertos, para obtener información relacionada sobre los procesos de formación previa recibidos, significación de los contenidos, objetivos, materiales, metodologías y actividades utilizadas, criterios de evaluación.

b) Pruebas de dominio objetivo con la finalidad de conocer las condiciones de entrada de cada estudiante. Para la evaluación de tareas, se usan tres pruebas de dominio relacionadas con variables independientes una vez validado su contenido y definidos tanto los estándares de superación como los puntos de corte para la clasificación de 6 niveles de realización de una acción concreta: 0 no sabe, 1 nunca, 2 casi nunca, 3 con frecuencia, 4 casi siempre, 5 siempre. Esta escala Likert permite situarnos en un nivel de competencia avanzado, medio, básico o no competente.

c) Cuestionario en línea sobre las opiniones de los estudiantes, para extraer percepciones y sentimientos.

El diseño de estas pruebas sigue la secuencia (Tabla 1) según Jornet et al. (2011). 
Percepción de los estudiantes de Maestro de Educación Primaria sobre su competencia digital: urgencias formativas detectadas JaVier Fombona y Maria Angeles Pascual

Tabla 1

Procedimiento para elaborar instrumentos para evaluar competencias

\begin{tabular}{cll}
\hline $\begin{array}{c}\text { Definir operativamente el } \\
\text { constructo (Competencias) }\end{array}$ & Fase 1 & $\begin{array}{l}\text { Determinar y especificar el Dominio } \\
\text { Competencial del constructo a evaluar. }\end{array}$ \\
\cline { 2 - 3 } & Fase 2 & Definir criterios de evaluación \\
\cline { 2 - 3 } & Fase 3 & $\begin{array}{l}\text { Especificar previamente un referente o } \\
\text { Estándar de Ejecución, para determinar } \\
\text { criterios de evaluación. }\end{array}$ \\
\hline
\end{tabular}

Determinar métodos, téc- Fase 4 Sistematizar el proceso de recolección nicas e instrumento de de evidencias. evaluación

Fase 5 Determinar el sistema de evaluación, instrumentos, recursos y técnicas de recogida de información: Indicadores.

Especificar el sistema de Fase 6 Definición de un sistema de comparapuntuación ción de evidencias con el Estándar.

Fase 7 Determinar el proceso de formación de la decisión (por ejemplo, Competente vs. No competente).

Uso de la información: Co- Fase 8 Especificación de los mecanismos de inmunicación formación a las audiencias y retroalimentación para el estudiante.

Planificar el análisis de Fase 9 Diseño de los mecanismos o criterios de calidad del sistema de evacalidad del propio sistema de evaluación. luación

Fuente: Jornet et al. (2011).

La primera fase en la construcción del instrumento define de manera operativa las competencias y sus subcompetencias. Para ello, se parte de un análisis documental que genera los núcleos temáticos para los grupos de discusión con expertos académicos y profesionales sobre el constructo o competencia. La segunda fase estará destinada a elaborar criterios de evaluación de los constructos que conforman cada instrumento de modo que sean representativos, explícitos, operativos y viables respecto a la medición. Para ello, se lleva a cabo un análisis inter-jueces conformados por académicos profesionales especialistas en la temática. La fase tercera se dirige a la elaboración por consenso entre expertos de estándares graduales: nivel de habilitación no competente, nivel básico de habilitación en la competencia, nivel medio de habilitación en la competencia, y nivel avanzado de habilitación en la competencia. Los diferentes niveles de habilitación son elementos discriminativos entre di- 
Percepción de los estudiantes de Maestro de Educación Primaria sobre su competencia digital: urgencias formativas detectadas

Javier Fombona y Maria Angeles Pascual

chos grados de habilitación. La fiabilidad de este análisis sigue el índice de congruencia de Hambleton y Rovinelli (1986). Las siguientes fases conllevan más depuración de los instrumentos, seleccionando el grupo de ítems sometido a estudio desde la Teoría de la Respuesta al Ítem basado en el modelo logístico de un parámetro de Rasch para modelos dicotómicos, esto es en el modelo estructural para los ítems de un test. Desde este modelo se considera que el cociente entre la probabilidad de que una repuesta sea correcta respecto a una respuesta incorrecta, es función del nivel de habilitación de la persona y el nivel de dificultad del ítem. A partir de ahí se comprueba: a) lo supuestos de independencia local y unidimensionalidad; y b) la calibración de los ítems respecto el modelo teórico. Para ello, se usaran diferentes programas (BILOG, LISREL...) ya que no existe un programa completo capaz de dar respuesta, a la vez, a dichas comprobaciones.

Como técnicas de análisis se usan medidas de tendencia central, medidas de dispersión, para la diferencia de medias Anovas de una vía con test de Tukey para las variables descriptivas politómicas. Para medir los criterios de normalidad y homocedasticidad creo que esto está mal escrito se usan pruebas de Kolmogorov y Levene, respectivamente. Como han puesto de manifiesto diferentes autores, con muestras que superan los cien integrantes se puede contar con pruebas paramétricas o pruebas de $W$ de Wilcoxon y $U$ de Mann-Whitney.

Así y específicamente para este caso, la investigación analiza los estudiantes universitarios del Grado de Maestro en su competencia digital a través de un cuestionario con 51 ítems (Tabla 2) que mide las siguientes áreas:

1- Acceso a la información. Esta área tiene 11 ítems que cuantifican el uso de buscadores de información en la red Internet, la evaluación de esa información y su gestión.

2-Comunicación. Esta área tiene 14 ítems relacionados con el nivel de manejo de herramientas de comunicación personal, el uso de aplicaciones para la presentación de información, la comunicación social, y la gestión de la identidad digital.

3-Creación de contenidos. Esta área tiene 11 ítems que miden el nivel de gestión y desarrollo de contenidos textuales y audiovisuales, la consideración de los derechos de autor, y la capacidad de manejo de las herramientas de creación de contenidos digitales.

4- Seguridad. Esta área tiene 7 ítems, varios relacionados con la pro- 
tección ante amenazas, la gestión de la identidad, la salud y el medio ambiente.

5- Resolución de problemas. Esta área tiene 8 ítems vinculados al nivel de superación de problemas técnicos. La identificación de necesidades y respuestas tecnológicas, el uso creativo de la tecnología, y la detección de lagunas en el conocimiento relacionado.

\section{Datos y rigurosidad del análisis}

La tabla 2 muestra el cuestionario aplicado y sus resultados en base a medidas de tendencia central, media y mediana, y medidas de dispersión, desviación típica. El cuestionario sigue las pautas del test de García y Musitu (2001) y su administración se ejecutó de forma telemática a través de plataforma virtual.

Tabla 2

Cuestionario sobre nivel de competencia digital y resultados

Ítem $\quad \begin{gathered}\text { Medida tendencia Dispersión } \\ \text { central }\end{gathered}$

Área competencial: acceso a la información

\begin{tabular}{l}
$\begin{array}{l}\text { Unidad de competencia: navegar, búscar y fil- } \\
\text { trar de información }\end{array}$ \\
\hline$(1)$ Conf
\end{tabular}

(1) Configuración del navegador web (Chrome, $3,0394 \quad 3,0000 \quad 1,37119$ Mozilla, Explorer,...) si es necesario

(2) Seleccionar las fuentes de información con $3,1592 \quad 3,0000 \quad 1,02376$ interés profesional

(3) Localizar información digitalizada usando

palabras clave y filtros y así ajustar y limitar la $3,3238 \quad 3,000 \quad 1,28012$ búsqueda

\begin{tabular}{llll}
\hline (4) Usar distintos buscadores (Google, Yahoo...) & 3,1431 & 3,000 & 1,34041 \\
para localizar información y recursos
\end{tabular}

$\begin{array}{llll}\text { Unidad de competencia: evaluar información } & \text { M. } & \text { MD. } & \text { DT. }\end{array}$

(5) Se consideran las restricciones de los recur-

sos educativos publicados y sus derechos de 3,0912 3,000 1,48972 autor

\begin{tabular}{llll}
\hline $\begin{array}{l}\text { (6) Se usan recursos educativos de Internet se- } \\
\text { gún las demandas de las asignaturas }\end{array}$ & 4,6547 & 4,000 & 1,07122 \\
$\begin{array}{l}\text { (7) Se evalúa la información localizada en in- } \\
\text { ternet posicionándose en un enfoque }\end{array}$ & 3,3667 & 3,000 & 1,08412 \\
\hline
\end{tabular}


Percepción de los estudiantes de Maestro de Educación Primaria sobre su competencia digital: urgencias formativas detectadas

Javier Fombona y Maria Angeles Pascual

\begin{tabular}{|c|c|c|c|}
\hline \multirow{2}{*}{$\begin{array}{l}\text { Ítem } \\
\text { Unidad de competencia: almacenar y recupe- } \\
\text { rar información }\end{array}$} & \multicolumn{2}{|c|}{$\begin{array}{l}\text { Medida tendencia } \\
\text { central }\end{array}$} & \multirow{2}{*}{$\begin{array}{c}\text { Dispersión } \\
\text { DT. }\end{array}$} \\
\hline & M. & MD. & \\
\hline $\begin{array}{l}\text { (8) Se guarda información con diferentes for- } \\
\text { matos (imágenes, texto, vídeos y páginas web) } \\
\text { clasificándola de forma que la puedas recupe- } \\
\text { rar fácilmente }\end{array}$ & 3,9535 & 4,000 & 1,11907 \\
\hline $\begin{array}{l}\text { (9) Se realizan copias de seguridad de la infor- } \\
\text { mación que consideras relevante }\end{array}$ & 3,5420 & 4,000 & 1,32034 \\
\hline $\begin{array}{l}\text { (10) Se usan espacios para almacenamiento } \\
\text { (discos duros, nubes y memorias USB) }\end{array}$ & 3,7281 & 4,000 & 1,32840 \\
\hline $\begin{array}{l}\text { (11) Se usa algún tipo de programa informático } \\
\text { para organizar, etiquetando los recursos conse- } \\
\text { guidos en la red internet }\end{array}$ & & 2,000 & 1,45453 \\
\hline \multicolumn{4}{|l|}{ Área competencial: comunicación } \\
\hline $\begin{array}{l}\text { Unidad de competencia: interacción con me- } \\
\text { dios digitales }\end{array}$ & M. & MD. & DT. \\
\hline
\end{tabular}

(12) Se usan 3 o más herramientas digitales y así interactuar (correo electrónico, whatsapp, video-chat, mensajes de voz, redes sociales, 4,7388 5,000 ,68766 etc.)

(13) Al navegar se interacciona con otras fuen-

tes de información digital (imágenes, enlaces, 4,2343 5,000 ,90627 audios, vídeos, repositorios de descarga)

\begin{tabular}{l}
$\begin{array}{l}\text { Unidad de competencia: compartir informa- } \\
\text { ción y contenidos }\end{array}$ \\
\hline
\end{tabular}

(14) Al compartir información o contenidos ob-

tenidos en línea, se cita a los autores y la fuente, 3,1360 3,000 1,25128

siguiendo las normas existentes

(15) Se seleccionan, noticias y recursos locali-

zados en varias páginas web, foros y otras co- 3,0698 3,0000 $\quad 1,15336$

munidades on-line para compartir en red

(16) Se usan programas para hacer presenta-

ciones digitales proyectables (Prezi, Slideshare, 3,2129 3,0000 1,30182

Scribd...)

(17) Se difunde on-line presentaciones digitales

hechas para enviar por correo, redes sociales, 2,7406 3,0000 $\quad 1,31260$

o subir a repositorios, etc. 


\begin{tabular}{|c|c|c|c|}
\hline Ítem & $\begin{array}{r}\text { Medida } t \\
\text { cer }\end{array}$ & $\begin{array}{l}\text { endencia } \\
\text { tral }\end{array}$ & Dispersión \\
\hline $\begin{array}{l}\text { Unidad de competencia: participación ciuda- } \\
\text { dana en línea }\end{array}$ & M. & MD. & DT. \\
\hline $\begin{array}{l}\text { (18) Se participa } 2 \text { o más comunidades redes } \\
\text { sociales (Facebook, Twitter, Instagram, Sanp- } \\
\text { chat, Linkedin, Pinterest, foros temáticos, etc.) }\end{array}$ & 4,4 & 5,0000 & 1,03116 \\
\hline $\begin{array}{l}\text { (19) Se aprovechan las opciones de los medios } \\
\text { digitales incluyendo a las redes sociales para } \\
\text { promover la participación social de la ciuda- } \\
\text { danía }\end{array}$ & 3,2934 & 3,0000 & 1,19128 \\
\hline $\begin{array}{l}\text { Unidad de competencia: colaboración me- } \\
\text { diante medios digitales }\end{array}$ & M. & MD. & DT. \\
\hline $\begin{array}{l}\text { (20) Se usan herramientas colaborativas en lí- } \\
\text { nea para compartir conocimiento (Google Dri- } \\
\text { ve, Dropbox, Zohodocs, Skype, Oovoo, etc.). }\end{array}$ & 2 & 3,0000 & 1,08715 \\
\hline
\end{tabular}

\begin{tabular}{llll}
\hline Unidad de competencia: netiqueta & M. & MD. & DT.
\end{tabular}

(21) Se consultan disposiciones legales sobre derechos y deberes de los que emitimos y reci- 2,4079 2,0000 $\quad 1,38670$ bimos mensajes digitales

\begin{tabular}{lllll}
\hline $\begin{array}{l}\text { (22) Al emitir y recibir mensajes cumples las } \\
\text { normas sobre la transferencia de información }\end{array}$ & 3,7299 & \multirow{2}{*}{3,0000} & 1,97757 \\
\hline
\end{tabular}

(23) Se considentan las características socio-

culturales de la audiencia a la que se dirigen $3,4776 \quad 3,0000 \quad 1,45387$

los mensajes digitales en internet

\begin{tabular}{llll}
\hline $\begin{array}{l}\text { Unidad de competencia: gestión de la identi- } \\
\text { dad digital }\end{array}$ & M. & MD. & DT. \\
\hline
\end{tabular}

(24) Gestionas tu identidad digital, cuidando

de hacer públicos solo aquellos datos persona- 4,4150 5,0000 $\quad$,95575

les que deseas que se conozcan

(25) Rastreas tu huella digital en Internet (datos,

fotografías, vídeos e informaciones que publi- 2,8658 3,0000 $\quad$ 1,90591

cas) para conocer su difusión

Área competencial: creación de contenidos

Unidad de competencia: contenidos desarrollados

M. MD. DT.

\begin{tabular}{llll}
\hline $\begin{array}{l}\text { 26) Compartes materiales digitales sencillos en } \\
\text { red (texto, vídeos, imágenes, audios,...) }\end{array}$ & 3,7639 & 4,0000 & 1,06662 \\
\hline $\begin{array}{l}\text { (27) Gestionas espacios web donde publicar } \\
\text { contenidos multimedia elaborados por ti. }\end{array}$ & 2,5206 & 2,0000 & 1,31813 \\
\hline
\end{tabular}


Percepción de los estudiantes de Maestro de Educación Primaria sobre su competencia digital: urgencias formativas detectadas

Javier Fombona y Maria Angeles Pascual

Ítem

Medida tendencia

central

Dispersión

(28) Al crear mensajes adaptados a su conteni-

do y formato a las características de los canales

de comunicación digital en los que los vas a 3,5886 3,0000 1,23376

difundir (redes sociales, YouTube, correo elec-

trónico, mensajería instantánea, etc.).

\begin{tabular}{lllll}
\hline (29) Trabajas audio digital mezclando voz y & 2,3363 & 2,0000 & 1,23333
\end{tabular} música.

$2,3363-2,0000-1,23333$

(30) Diseñas y creas presentaciones de tipo digital mezclando imágenes, gráficos y textos.

$3,4186 \quad 3,000 \quad 1,14851$

(31) Creas vídeos propios insertando imágenes, gráficos, fragmentos de películas y textos.

$2,8175 \quad 3,0000 \quad 1,25537$

Unidad de competencia: integración y reestructuración

M. MD. DT.

(32) Se utilizan programas digitales de edición

de audio-vídeo para modificar contenidos 2,7567 3,0000 1,81141

creados por ti o por otros autores

Unidad de competencia: derechos de autor y

licencias

(33) Existe preocupación por saber la norma

que regula los derechos de autor y la licencia $\quad 2,5170 \quad 2,0000 \quad 1,35307$

elegida para protegerlos.

(34) Se respetan los derechos previstos y las

obligaciones previstas en las normativas que

regulan el uso de los materiales de los distintos

$3,3775 \quad 3,0000 \quad 1,54349$

autores.

(35) Hay interés en conocer procedimientos

por los que el autor libera los derechos y hace $2,6476 \quad 2,0000 \quad 1,58486$

la obra pública y gratuita.

\begin{tabular}{llll}
\hline Unidad de competencia: programación & M. & MD. & DT. \\
\hline
\end{tabular}

(36) Modificas la configuración básica de las

herramientas y medios digitales que dispones,

para adaptarla a tus necesidades (teclado, im-

$3,3148 \quad 3,0000 \quad 1,30108$

presora, pantalla...).

Área competencial: seguridad

Unidad de competencia: protección de dispositivos

M. MD. DT.

(37) Se hacen tareas de mantenimiento y protección de dispositivos usados: actualizaciones

de sistemas, gestión de antivirus, contraseñas,

$3,8819 \quad 4,0000 \quad 1,11860$

etc. 
Percepción de los estudiantes de Maestro de Educación Primaria sobre su competencia digital: urgencias formativas detectadas JaVier Fombona y Maria Angeles Pascual

Ítem

Medida tendencia central

Dispersión

(38) Sabes cómo actuar cuando detectas una

amenaza de seguridad en tus dispositivos y $3,4114 \quad 3,000 \quad 1,25821$

equipos.

Unidad de competencia: protección de datos personales e identidad digital

M. MD. DT.

\begin{tabular}{llll}
\hline (39) Proteges los datos personales sensibles. & 4,3274 & 5,0000 & 1,02574
\end{tabular}

(40) Proteges tu identidad digital y la de los demás.

$4,2665 \quad 5,0000 \quad, 95910$

Unidad de competencia: protección de la sa-

lud

(41) Te preocupan los riesgos de salud que pueden asociarse con el uso inadecuado de dispositivos y equipos electrónicos (efectos pos- 3,6637 4,0000 1,29153 turales y ergonómicos, cansancio, conductas adictivas, radiaciones, etc.)

\begin{tabular}{l}
$\begin{array}{l}\text { Unidad de competencia: protección del entor- } \\
\text { no }\end{array}$ \\
\hline
\end{tabular}

(42) Haces un uso óptimo de los dispositivos

digitales para que tengan el menor impacto so- 3,3810 $\quad 3,0000 \quad$ 1,30056

bre el medio ambiente

(43) Adoptas medidas eficaces de ahorro ener-

gético y de alargamiento de la duración de las 3,7048 4,0000 1,76399

baterías de tus dispositivos digitales.

Área competencial: Resolución de problemas

Unidad de competencia: resolver problemas técnicos

M. MD. DT.

(44) ¿Sabes adoptar medidas eficaces de ahorro

energético y de alargamiento de la duración de $\quad 2,925 \quad 3,000 \quad 1,2635$

las baterías?

(45) Se solucionan problemas técnicos básicos

relacionados con entornos digitales habituales

y dispositivos, con la ayuda de un manual o 2,9696 3,0000 1,19623

información técnica.

\begin{tabular}{lccc}
\hline $\begin{array}{l}\text { Unidad de aprendizaje: identificar las necesi- } \\
\text { dades y las respuestas tecnológicas }\end{array}$ & M. & MD. & DT. \\
\hline $\begin{array}{l}\text { (46) Utilizas entornos virtuales para seguir cur- } \\
\text { sos en red para tu formación. }\end{array}$ & 2,7013 & 3,0000 & 1,25232 \\
\hline $\begin{array}{l}\text { (47) Consultas foros especializados que te ayu- } \\
\text { den a resolver dudas o problemas. }\end{array}$ & 3,3757 & 3,0000 & 1,13364 \\
\hline
\end{tabular}


Percepción de los estudiantes de Maestro de Educación Primaria sobre su competencia digital: urgencias formativas detectadas

Javier Fombona y Maria Angeles Pascual

\begin{tabular}{lccc}
\hline Ítem & $\begin{array}{c}\text { Medida tendencia } \\
\text { central }\end{array}$ & Dispersión \\
\hline $\begin{array}{l}\text { Unidad de aprendizaje: innovar y usar la tec- } \\
\text { nología creativamente }\end{array}$ & M. & MD. & DT. \\
\hline $\begin{array}{l}\text { (48) Se usan las tecnologías académicamente } \\
\text { para buscar soluciones de forma innovadora } \\
\text { para facilitar el aprendizaje. }\end{array}$ & 3,9141 & 4,0000 &, 97448 \\
$\begin{array}{l}\text { (49) Se usan las tecnologías diariamente para } \\
\text { participar en proyectos creativos y para gestio- } \\
\text { nar soluciones innovadoras. }\end{array}$ & 4,0000 & 1,12891 \\
$\begin{array}{l}\text { Unidad de aprendizaje: identificar lagunas en } \\
\text { la competencia digital }\end{array}$ & M. & MD. & DT. \\
\hline $\begin{array}{l}\text { (50) Se reconoce la existencia de carencias so- } \\
\text { bre el uso de recursos digitales para el aprendi- 3,7048 }\end{array}$ & 4,0000 & 1,17950 \\
$\begin{array}{l}\text { zaje profesional docente. } \\
\begin{array}{l}\text { (51) Se experimenta con nuevas tecnologías di- } \\
\text { gitales para cubrir algunas lagunas en la com- }\end{array} \\
\begin{array}{l}\text { petencia digital, precisa en el aprendizaje } \\
\hline\end{array}\end{array}$ & 3,0000 & 1,14880 \\
\hline
\end{tabular}

La información recogida se ha sometido a la técnica multivariante de análisis factorial para reducirla, estandarizarla y validarla. Este análisis se ha realizado a través del procedimiento de componentes principales (PrC) con fines exploratorios.

La determinación del número de factores se ha elaborado según el criterio de raíz latente de Kaiser-Meyer-Olkin. Posteriormente se ha aplicado la rotación de máxima varianza con normalización de Kaiser, obteniendo unos resultados de Meyer-Olkin 0,867; en la Prueba de esfericidad según Bartlett Chi-cuadrado se ha obtenido 7260,477; en Gl. ha sido de 1275; y la Sig. fue nula. La esfericidad de Bartlett confirma la existencia de factores subyacentes en la matriz de datos, por su alto nivel de significación obtenido. Se ha optado por un índice de discriminación con un valor fijado en 0,5 , y la validez de constructo se ha considerado para las 51 cuestiones. El análisis factorial se rige por 3 factores englobando los 19 ítems iniciales (Tabla 3), ello nos explica el 31,268\% del total de varianza, considerando 0,5 el nivel mínimo de discriminación. 
Percepción de los estudiantes de Maestro de Educación Primaria sobre su competencia digital: urgencias formativas detectadas Javier Fombona y Maria Angeles Pascual

Tabla 3

Factores de los ítems que explican la varianza y se agrupan en factores (Rotación Varimax)

\begin{tabular}{lll}
\hline Factores & Varianza explicada por factor & Ítem que integran cada factor \\
\hline F-1 & $16,978 \%$ & $1,10,37,38,44,45,47$, \\
\hline F-2 & $5,508 \%$ & $14,21,22,23,33,34,35$ \\
\hline F-3 & $5,031 \%$ & $27,29,31,32$ \\
\hline F-4 & $3,799 \%$ & $12,13,24$ \\
\hline $\begin{array}{l}\text { Varianza total } \\
\text { explicada }\end{array}$ & $31,316 \%$ & \\
\hline$N^{\circ}$ de factores & 5 & \\
\hline
\end{tabular}

La fiabilidad cuantifica la estabilidad de la medición en diferentes momentos. Así, el Alfa de Cronbach es un parámetro en relación al total de la escala y su valor es de 0,786 . Se ha procedido a ir eliminando cada ítem y ello sugiere que el ítem $\mathrm{n}^{\circ} 33=0,770$ valor menor que $0,789 \mathrm{e}$ igual al $n^{\circ} 22$. Sin suprimir ninguno ítem el valor resultante no genera un alfa superior al total de la escala $(0,791)$. Con la intención de saber el grado de consistencia se utiliza el Alfa entre las 2 partes del cuestionario y obteniendo en los ítems impares un valor de Alfa igual a 0,695; mientras que en los pares se obtiene un valor de 0,710; así existe una consistencia razonable en la fiabilidad entre ítems pares e impares. Al no ser la correlación total de elementos corregida de ningún ítem de la escala cero o negativa (ítems $33=.470>.123=$ Ítem 12) no se suprime ningún ítem, quedando integrada la escala por las dimensiones e ítems que figura en la tabla $n^{\circ} 2$; es decir, 51 ítems.

\section{Análisis de los datos}

El análisis de las medidas de tendencia central y dispersión pone de manifiesto que los alumnos analizados presentan déficit en estas acciones (por orden de mayor carencia):

- (29) Creas sonido digital con voz y música.

- (11) Utilizas algún tipo de programa informático para organizar, etiquetando los recursos conseguidos en la red internet.

- (21) Consultas la norma que regula deberes y derechos de los que emiten y reciben mensajes. 
Percepción de los estudiantes de Maestro de Educación Primaria sobre su competencia digital: urgencias formativas detectadas

Javier Fombona y Maria Angeles Pascual

- (33) Te preocupas por saber la norma sobre los derechos de autor y el tipo de licencia que se elige para protegerlos.

- (27) Gestionas espacios web donde publicar contenidos multimedia elaborados por ti.

- (35) Te preocupas por saber las normas por las que un autor libera los derechos para hacer la obra pública y gratuita.

- (32) Usas programas de edición digital (de audio y/o vídeo) para modificar contenidos creados por ti o por otros autores.

- (17) Se difunden on-line presentaciones creadas y enviadas por correo, redes sociales, subida a repositorios, etc.

- (25) Rastreas tu huella digital en Internet (datos, fotografías, vídeos e informaciones que publicas) para conocer su difusión.

- (31) Produces material gráfico con fotos, gráficos, fragmentos de películas y textos.

Estos ítems poseen una media inferior y evidencian la realización de esas acciones con frecuencia reducida, consiguientemente necesitan apoyo para su desempeño más frecuente. Mientras que las siguientes son las unidades de competencia digital que más dominan (en escala de mayor a menor dominio):

- (12) Se usan 3 o más herramientas digitales distintas para interactuar con otras personas (correo electrónico, whatsapp, video-chat, mensajes de voz, redes sociales, etc.).

- (18) Participas en 2 o más comunidades o en redes sociales (Facebook, Twitter, Instagram, Snapchat, Linkedin, Pinterest, foros temáticos, etc.).

- (24) Gestionas tu identidad digital, cuidando de hacer públicos solo aquellos datos personales que deseas que se conozcan.

- (39) Proteges los datos personales sensibles.

- (40) Proteges tu identidad digital y la de los demás.

- (13) Se interacciona con varias fuentes de información digital (imágenes, enlaces, audios, vídeos, repositorios de descarga) cuando se está navegando.

La desviación típica de los ítems indica que la dispersión de las puntuaciones es media, ya que la sigma oscila entre Ítem $n^{\circ} 12=, 68766<$ $1,97757=$ Ítem 22. Son significativos los casos en los que las medianas son inferiores a sus respectivas medias y, por consiguiente hay más casos 
superiores a la media; y los casos en los que las medianas son superiores a las medias y, por consiguiente, hay más casos con puntuaciones por debajo de la media.

\section{9.- Discusión y conclusiones}

En primer lugar se observa que esta investigación ha concretado la ambivalencia de competencia digital a través de las dimensiones descritas en el cuestionario aplicado, y estas dimensiones coinciden con las comúnmente analizadas, ya sea en las áreas prioritarias para el Instituto Nacional de Tecnologías Educativas y de Formación del Profesorado (INTEF, 2017), sea con los contenidos impartidos en varios grados de Maestro en Educación (Gewerc y Montero, 2015), o con otras investigaciones (Valverde-Crespo, Pro-Bueno, González-Sánchez, 2018; Vuorikari et al., 2016).

Los datos obtenidos reiteran determinadas lagunas en su formación relacionada con la gestión de audio y video digital, la organización de los recursos, con los contenidos descargados de Internet, la normativa sobre derechos y deberes, la protección del autor y sus documentos, y la gestión de la huella digital. Estas carencias giran en torno a aspectos ya mencionados por Barragán Sánchez y Buzón García (2004, 107), que resaltaron la necesidad de desarrollar competencias instrumentales centradas en habilidades específicas en la informática, en la habilidad para elaborar un guión multimedia, para usar distintos recursos y programas en el diseño, para crear los ficheros o archivos que se comparten en la Web, para aplicar teorías y modelos al análisis y valoración de recursos y prácticas educativas, para seleccionar y valorar la información de la red.

Por otro lado las lagunas en el conocimiento de los estudiantes, relacionadas con su conocimiento sobre las disposiciones legales, los derechos de los autores y su huella digital, no han sido detectadas previamente en otra literatura científica consultada. Todo parece indicar que es una nueva prioridad en la formación. A este carácter novedoso se une la problemática que se genera con la irrupción de estas nuevas tecnologías en el aula, aspecto emergente a nivel social y educativo (Rial et al., 2018; Rodríguez-Gómez, Castro y Meneses, 2018; Rojas, JiménezFernández y Rodríguez, 2018)

En el caso contrario, aparece como correcto el dominio de herra- 
Percepción de los estudiantes de Maestro de Educación Primaria sobre su competencia digital: urgencias formativas detectadas

Javier Fombona y Maria Angeles Pascual

mientas digitales diferentes para interactuar con los demás (correo electrónico, whatsapp, video-chat, mensajes de voz, redes sociales, etc.), así como la participación activa en comunidades virtuales y redes sociales. También es adecuado el nivel de gestión de la identidad digital, la protección de datos personales, y la interacción con distintas fuentes de información. Estas fortalezas rebajarían la necesidad de continuar dando peso formativo al análisis de información derivada de distintas fuentes, a la participación en redes (Theunert, 1999), al desarrollo de la capacidad operativa social y cultural (Mikos, 1999), o a la interacción y colaboración en el contexto educativo (Gewerc, Montero y Lama, 2014).

Coincidimos con Aslan y Zhu (2016) al proponer nuevas dimensiones en la formación relacionada con la competencia digital. Creemos que se debe de incrementar la experimentación del componente práctico aplicado del futuro profesorado, como también indica Montero (2018). Así el docente tiene que afrontar nuevos retos y abordar exitosamente nuevos desafíos generados por las TIC, ya sean aspectos técnicos, legislativos, o cuestiones relacionadas con la seguridad tales como el acoso o la ansiedad derivado del uso de las TIC. Este incremento en los contenidos no debe ser óbice para continuar abordando temas tradicionales y de elevado impacto, como la alfabetización audiovisual, dado que los datos indican que estos aspectos se vuelven nuevamente lagunas del conocimiento.

\section{Referencias}

Aslan, A. y Zhu, C. (2016). Influencing factors and integration of ICT into teaching practices of pre-service and starting teachers. International Journal of Research in Education and Science, 2(2), 359-370.

Barragán, R. y Buzón, O. (2004). Desarrollo de Competencias Específicas en la materia Tecnología Educativa bajo el marco del Espacio Europeo de Educación Superior. RELATEC, 3(1).

Comisión Europea (2006). Competencias clave para el aprendizaje permanente. Recomendación 2006/962/CE del Parlamento Europeo y del Consejo, de 18 de diciembre de 2006, sobre las competencias clave para el aprendizaje permanente. Diario Oficial L 394 de 30.12.2006.

Consejo de la Unión Europea (2006). Recommendation of the European Union and of the Council of 18 December 2006 on key competences for lifelong learning (2006/962/ EC). Official Journal of the European Union. Recuperado de https://goo.gl/3HRXmb $(30 / 12 / 2006)$ 
Percepción de los estudiantes de Maestro de Educación Primaria sobre su competencia digital: urgencias formativas detectadas Javier Fombona y Maria Angeles Pascual

Cuartero, M.; Gutiérrez, I. y Prendes, M. (2016). Análisis conceptual de modelos de competencia digital del profesorado universitario. RELATEC, 15(1), 97-114.

Dolana, M. (2012). Reforming teacher education in the context of lifelong learning: the case of the Bed degree programme in Ireland. European Journal of Teacher Education, 35(4), 463-479.

Ferrari, A. (2012). Digital Competence in Practice: An Analysis of Frameworks. Sevilla: JRC-IPTS. Disponible (01/07/13) en: http://ftp.jrc.es/EURdoc/JRC68116.pdf.

Fombona, J. (2003). Nuevas tecnologías aplicadas (y aplicables) a la educación: NNTTAE. Comunicación y pedagogía, 189, 19-22.

Fombona, J., Rodríguez, C. y Barriada, C. (2012). Gestión de incidencias informáticas: el caso de la Universidad de Oviedo y la Facultad de Formación del Profesorado. RUSC Universities and Knowledge Society Journal. 9(2), 100-114.

Gallardo, E.; Minelli, J.; Marqués, L. y Esteve, F. (2015). Digital Competence in Knowledge Society.

Gallego-Arrufat, J. (1995). Formación y desarrollo profesional de profesores usuarios de ordenadores. Revista interuniversitaria de formación del profesorado, 23, 107-119.

García, F.J. y Musitu, G. (2001). AF5, Autoconcepto Forma 5 (2a edición). Madrid, España: TEA Ediciones, S.A.

García, M.S.; Pascual, M.A. y Fombona, J. (2011). Las competencias en el prácticum del Máster en formación del profesorado de Educación Secundaria Obligatoria, Bachillerato y Formación Profesional. Magister, 24, 109 - 119.

Gewerc, A.; Montero, M. y Lama, M. (2014). Colaboración y redes sociales en la enseñanza universitaria. Comunicar, 42, 55-63.

Gewerc, A. y Montero, A. (2015). Conocimiento profesional y competencia digital en la formación del profesorado. El caso del Grado de Maestro en Educación Primaria. Relatec. 14(1), 31-43. DOI: 10.17398/1695288X.14.1.31

Gisbert, M. y Esteve, F. (2011). Digital learners: La competencia digital de los estudiantes universitarios. La Cuestión Universitaria, (7), 4859

Gisbert, M.; Espuny, C. y González, J. (2011). Cómo trabajar la competencia digital con estudiantes universitarios. En Rosabel Roig-Vila, Cosimo Laneve (Coord.). La práctica educativa en la Sociedad de la Información: Innovación a través de la investigación, Alcoy - Brescia: Marfil \& La Scuola, 157-174.

Hambleton, R. y Rovinelli, R. (1986). Assessing the dimensionality of a set of test items. Applied psychological measurement, 10, 287-302.

INTEF (2015). Marco de Competencia Digital Docente. Recuperado de https://goo.gl/ t2rK5k (13/10/2015)

INTEF (2017). Marco Común de Competencia Digital Docente. Madrid: Ministerio de Educación, Cultura y Deporte. Recuperado de https://goo.gl/s22LdZ (12/9/2018)

Jornet, J.; González-Such, J.; Suárez, J. y Perales, M. (2011). Diseño de procesos de evaluación de competencias. Bordón. 63, 1, 125-145.

Kim. Ch.; Kim, M.K.; Lee, Ch.; Spector, J.M. y DeMeester, K. (2013). Teacher beliefs and technology integration. Teaching and Teacher Education, 29, 76 - 85.

Krumsvik, R. (2011). Digital competence in Norwegian teacher education and schools. Högre utbildning, 1(1), 3951. 
Percepción de los estudiantes de Maestro de Educación Primaria sobre su competencia digital: urgencias formativas detectadas

Javier Fombona y Maria Angeles Pascual

Legorreta, B. y López, E. (2005). Especialidad en Tecnología Educativa de la UAEH. En Virtual Educa, Mexico. Recuperado de https://goo.gl/2Fr9L3 (12 /2/ 2009).

Mikos, L. (1999). Medienkompetenz als präventiver Jugendschutz. Recuperado de http:// www.medienpaedagogik-online.de/mk/00386/druck.pdf (9/9/2012).

Montero, L. (2018). Relaciones entre teoría y práctica en la formación inicial. Percepciones de formadores y estudiantes del Grado de Maestro en Educación primaria. Educatio Siglo XXI, 36(2). DOI: https://doi.org/10.6018/j/333061

Muñoz, J.M.; Jiménez, N.N.; Adamuz, N. y Rubio, S. (2016). TIC y recursos mediáticos en el aula de Primaria Colección: Didáctica y Desarrollo. Madrid: Paraninfo.

Pérez-Ferra, M. (2013). La actitud indagadora del profesor: un proceso para desarrollar competencias en los docentes. Profesorado. Currículum y Formación del Profesorado, 17(3), $57-72$

Pérez Ferra, M. y Pantoja, A. (2006). Opinión del profesorado de Secundaria sobre los aspectos pedagógicos relacionados con el desarrollo de competencias profesionales en sus alumnos. Revista de Investigación Educativa, 24(2), 497-518.

Pozos, K. (2009). La Competencia Digital del Profesorado Universitario para la Sociedad del Conocimiento: Un Modelo para la Integración de la Competencia Digital en el Desarrollo Profesional Docente. En: TEJADA, J. et al. (Coord.) (2009). Estrategias de Innovación en la Formación para el Trabajo. Actas $V$ Congreso Internacional de Formación para el Trabajo. Madrid: Tornapunta.

Pozuelos, F.; Travé, G. y Cañal de León, P. (2010). Enseñanza basada en la indagación: concepciones, impedimentos y apoyo de los docentes, Teaching \& Education, 21(2), 131-142, DOI: 10.1080/10476210903494507

Prendes, P.; Castañeda, L. y Gutiérrez, I. (2010). Competencias para el uso de TIC de los futuros maestros. Comunicar, 35, 175-182.

Rial, A.; Golpe, S.; Isorna, M.; Brana, T. y Gómez, P. (2018). Minors and problematic Internet use: Evidence for better prevention. Computers in Human Behavior, 87, 140145. DOI: 10.1016/j.chb.2018.05.030

Rodríguez-Gómez, D.; Castro, D. y Meneses, J. (2018). Problematic uses of ICT among young people in their personal and school life. Comunicar, 56, 91-100. DOI: 10.3916/ C56-2018-09

Rojas, D.; Jiménez-Fernández, S. y Rodríguez, R. (2018). Management of time and use of ICT in university students. Pixel-Bit, 53, 109-121. DOI: 10.12795/pixelbit.2018. i53.07

Sierra, B.; Méndez-Giménez, A. y Mañana-Rodríguez, J. (2012). Necesidad y propuesta de un procedimiento para programar por Competencias Básicas. Aula Abierta, 40(3), 33-46.

Theunert, H. (1999). Medienkompetenz in Vor und Grudschulalter. En Fred Schell. Medienkompetenz. München. Kopäd.

UNESCO (1984). La Educación en materia de Comunicación. París: UNESCO.

Valverde-Crespo, D.; Pro-Bueno, A. y González-Sánchez, J. (2018). La competencia informacional-digital en la enseñanza y aprendizaje de las ciencias en la educación secundaria obligatoria actual: una revisión teórica. Eureka sobre Enseñanza y Divulgación de las Ciencias 15(2), 2105. 
Percepción de los estudiantes de Maestro de Educación Primaria sobre su competencia digital: urgencias formativas detectadas Javier Fombona y Maria Angeles Pascual

Vivancos, J. (2008). Tratamiento de la información y competencia digital. Madrid: Alianza Editorial.

Vuorikari, R.; Punie, Y.; Carretero, S. y Van den Brande G. (2016). DigComp 2.0: The Digital Competence Framework for Citizens. Update Phase 1: The Conceptual Reference Model. Luxembourg Publication Office of the European Union. EUR 27948 EN. DOI:10.2791/11517.

Este estudio se incluye en el proyecto I+D+I titulado "Evaluación y desarrollo de dos competencias genéricas en estudiantes de primer año del grado de maestro en educación primaria." Referencia: EDU201570491-R 
